\title{
Validity and reliability of the Thai version of the simple frailty questionnaire (T-FRAIL) with modifications to improve its diagnostic properties in the preoperative setting
}

\author{
Warut T.Sriwong ${ }^{1}$, Waroonkarn Mahavisessin ${ }^{2}$, Varalak Srinonprasert ${ }^{3,4}$, Arunotai Siriussawakul ${ }^{4,5}$, \\ Wichai Aekplakorn ${ }^{6}$, Panita Limpawattana ${ }^{7}$, Patumporn Suraarunsumrit ${ }^{3}$, Rachaneekorn Ramlee ${ }^{4}$ and \\ Titima Wongviriyawong ${ }^{3^{*}}$
}

\begin{abstract}
Background: Several methods are available for identifying frailty, but limited tools have been validated in Thai context. Our objective was to evaluate the validity and reliability of the Thai version of the Simple Frailty Questionnaire (T- FRAIL) compared to the Thai Frailty Index (TFI) and to explore modifications to improve its diagnostic properties.

Methods: The T-FRAIL was translated with permission using a standardized protocol, that included forward and backtranslation. Content validity analysis was performed using input from 5 geriatricians. Test-retest reliability, concurrent validity, diagnostic properties, and options to increase the sensitivity of the questionnaire were explored. A cross-sectional study for evaluation validity and reliability was carried out among 3 hundred patients aged 60 or more undergoing elective surgery at a university hospital.

Results: The item content validity index (I-CVI) showed 1.0 for each questionnaire item. Test-retest reliability within a 7-day interval was done in 30 patients with a good intraclass correlation coefficient of 0.880 . Compared with the TFI, the T-FRAIL yielded an excellent accuracy (area under the curve $=0.882$ ). The identification of frailty using a score of 2 points or more provided the best Youden's index at 63.1 with a sensitivity of $77.5 \%(95 \% \mathrm{Cl} 69.0-84.6)$ and a specificity of $85.6 \%$ (95\% CI 79.6-90.3). A cutoff point of 1 out of 5 items for original T-FRAIL provided a sensitivity of $93.3 \%$ and a specificity of $61.1 \%$. The modified T-FRAIL (T-FRAIL_M1), by reducing the "illnesses" criterion to 4 or more diseases, at a cutoff point at 1 had a sensitivity of $94.2 \%$ and a specificity of $57.8 \%$. Another modified T-FRAIL (T-FRAIL_M2), by combining three components, at a cutoff point at 1 yielded a sensitivity of $85.8 \%$ and a specificity of $80.6 \%$.

Conclusion: The T-FRAIL and its modification demonstrated satisfactory validity and reliability to identify frailty in elderly patients. The cutoff score of 1 point from 5 items from the original version of T-FRAIL and T-FRAIL_M1 provides a highly sensitive screening tool. T-FRAIL_M1 with a cutoff point of 2 and T-FRAIL_M2 yields reasonable sensitivity and specificity for practical use.
\end{abstract}

Keywords: Frailty, Elderly patients, Diagnosis, Translation, Validity, Reliability

\section{*Correspondence: titima.won@mahidol.ac.th}

${ }^{3}$ Division of Geriatric Medicine, Department of Medicine, Faculty

of Medicine Siriraj Hospital, Mahidol University, Bangkok 10700, Thailand

Full list of author information is available at the end of the article

\section{Background}

Frailty is a clinical syndrome characterized by reduced physiological body reserve that was originally described in older persons [1,2], but is increasingly identified in 
younger age groups [3-5]. This vulnerable state results in decreased responses to internal and external stressors that lead to negative clinical consequences [6]. Frailty has been associated with a higher number of comorbidities, increased incidence of falls, and more disability in older people [7-9]. Increased rates of hospital admission and mortality have been observed in studies of frailty $[10,11]$.

Frailty screening reliably classifies high-risk older patients in several medical contexts, including surgical care [12-14]. Frail patients are more likely to experience negative postoperative consequences $[15,16]$. One systematic review reported a strong relationship between frailty and major adverse cardiac events after cardiac surgery [17]. In cancer patients, frailty status predicts outcomes for many modalities of treatments, including patients undergoing surgical intervention [18].

Improved methods to identify frailty in older, surgical patients could lead to better perioperative care. Preoperative preparation including prehabilitation, correcting malnutrition, psychological intervention, and prevention of postoperative delirium have been recommended to improve the quality of care. Shared decision-making is also suggested to better prepare frail patients for surgery $[19,20]$. Intraoperative management of altered pharmacodynamic and pharmacokinetics [21], and postoperative multidisciplinary care in frail patients are also beneficial [22]. Therefore, frailty is included in the list for optimal preoperative assessment of older surgical patients guideline recommended by the American College of Surgeons National Surgical Quality Improvement Program and the American Geriatrics Society [23].

Several approaches have been proposed to identify frailty [2, 24-26]. Although the Fried criteria and Frailty Index have been widely cited in the literature, these tools are technically complex and time consuming. The FRAIL scale or Simple Frailty Questionnaire (SFQ), comprised of a 5-item, self-reported questionnaire, may be a more practical screening tool [5]. The FRAIL scale is increasingly accepted worldwide and many countries have validated it to their cultural context [5, 27-29].

Few studies have been conducted to assess the validity of frailty diagnosis in Thailand. The Thai Frailty Index (TFI) is constructed according to the accumulated deficits approach and is associated with mortality risk in older people [30]. However, administering the TFI is time consuming. The Simple Frailty Questionnaire could be preferable in busy clinical practices, including preoperative evaluation for elective surgery. Therefore, we performed a cross-cultural adaptation of the questionnaire, assessed its psychometric properties, and explored the optimal cutoff point for frailty in older patients at the surgical preoperative clinic.

\section{Methods}

\section{Design, setting, and participants}

The study aimed to perform a cross-cultural adaptation of the simple frailty questionnaire and assess its validity and reliability in comparison to the Thai Frailty Index in a preoperative setting. This study was conducted in accordance with the Declaration of Helsinki and was approved by Institutional Review Board, Faculty of Medicine Siriraj Hospital, Bangkok, Thailand (COA no. Si 397/2018). This cross sectional-study included 3 hundred patients from the Surgery outpatient clinic at Siriraj Hospital, enrolled from April 2019 to November 2020. Eligible participants were aged 60 years or over and were scheduled for elective surgery. The participants were excluded if they were unable to fluently communicate in Thai. After informed consent was obtained, baseline demographic data were recorded. The TFI and T-FRAIL were collected by two trained research assistants, separately.

\section{The Thai frailty index (TFI)}

The TFI was developed using accumulation deficit model and validated against mortality risk among community dwelling older people [30]. It was created following the suggested standard procedure [31] comprising 30 variables that included medical comorbidities, physical function, cognition and emotional health. The cutoff point of more than 0.25 was used for identifying frailty [30].

\section{The FRAIL scale and T-FRAIL questionnaires}

The FRAIL scale is, 5-item questionnaire for frailty screening. The questionnaire aims to "fatigue", "resistance", "ambulation", "illnesses" and "loss of weight". Each item required self-report response, which was rated as 1 and 0 points depending on the presence of characteristic in each criterion. The score range from 0 to 5 with higher score demonstrated more frailty characteristics. According to the original FRAIL scale, cutoff point of 3 or above were used to identify frail patient, while score of 2 indicated prefrail status [5]. The T-FRAIL was the Thai version translation of the FRAIL scale which was developed according to the following steps.

\section{Translation process}

Copyright permission for the Simple Frailty Questionnaire translation was granted by the owner, Professor John E. Morley, Division of Geriatric Medicine, Saint Louis University School of Medicine. The guideline for translation is adapted from 'guidelines for the process of cross-cultural adaptation of self-report measures' [32].

The translation process included six steps. 


\section{Step 1 initial translation}

The Simple Frailty Questionnaire (FRAIL) was translated from the original English questionnaire by two Thai bilingual independent translators. The first translator was a geriatrician from Siriraj Hospital who was invited to translate the questionnaire from a clinical perspective. The second one was a non-medical translator who translated the questionnaire by language aspect only.

\section{Step 2 synthesis of the translations}

The research team held the discussion at Siriraj Hospital to review the two Thai versions of the questionnaire in comparison with the original English version. Thai words were carefully chosen from both translations to construct a single version of the questionnaire.

\section{Step 3 Back-translation}

The Thai version of the questionnaire was sent to two independent language institutions for back-translation. The first translator was invited from the Translation and Interpretation Center, Faculty of Liberal Arts, Mahidol University. The second translator was a Canadian-Thai translator from a private sector organization. These two translators were native English speakers and had no medical background.

\section{Step 4 expert committee}

An expert committee from Siriraj Hospital was formed to evaluate semantic equivalence, idiom equivalence, experiential equivalence, and conceptual equivalence. The original translation, the Thai questionnaire, and two back-translation versions were included in the discussion.

\section{Step 5 test of the prefinal version}

A preliminary assessment with 10 elderly participants aged more than 65 years old who attended a geriatric clinic, was done to assess questionnaire comprehension. Most words were easily comprehended by the elders, while some were too difficult. Drawbacks of the current questionnaire were recorded.

\section{Step 6 submission of documentation to the developers}

The research team adapted and finalized the questionnaire according to the pilot study results. All papers including two back-translations and the finalized Thai questionnaire were sent to the owner of the original version.

\section{Validity and reliability assessment Content validity}

The Thai version of Simple Frailty Questionnaire (T-FRAIL) was evaluated by five independent geriatricians who were not involved in the translation process.
Each item of the translated questionnaire was rated in a 4 -point scale of ' $1=$ not relevant', ' $2=$ somewhat relevant', ' $3=$ quite relevant' and ' $4=$ highly relevant'.

\section{Test-retest reliability}

The test-retest reliability was conducted in 30 elderly patients on two occasions 7 days apart with the questionnaire items having been rearranged. Later scores were compared with former scores to identify the Intraclass correlation coefficient.

\section{Concurrent validity and diagnostic test assessment}

The concurrent validity including sensitivity, specificity, likelihood ratio for positive and negative results, and the positive and negative predictive value of the T-FRAIL were analyzed in comparison with the TFI as a reference standard. Spearman's correlation coefficient was estimated to address the correlation between the two tests.

\section{The T-FRAIL_M1 and the T-FRAIL_M2 questionnaires}

The original "illness" criterion in FRAIL scale required 5 or more underlying diseases to count as one score. Patients with several comorbidities were at higher risk of developing complications [33-36] and more likely to receive conservative treatment rather than undergoing surgeries [35-38]. The authors, therefore, anticipated that most patients recruited from preoperative setting for elective surgeries would have number of comorbidities less than 5 and might affect sensitivity of the test. Hence, we proposed T-FRAIL_M1 as a modification of T-FRAIL score by reducing illnesses criterion to 4 or more underlying diseases to determine whether this modification would improve test properties or not, in comparison with the original one. Another anticipated common underreported item would be the loss of weight as it was not a routine measurement among older people in our context. The modification of the questionnaire without this item was initially planned. Moreover, we believe that minimizing the items with reasonable diagnostic properties might facilitate the implementation of the test in busy clinical context. We, therefore, developed T-FRAIL_M2 by exploring the combination of 3 items in T-FRAIL and explore the diagnostic properties of those brief versions.

\section{Statistical analysis}

The content validity index for items (I-CVI) was chosen as the quantification method. Each item's I-CVI is calculated by the proportion of experts who rated ' 3 ' or ' 4 ' of all. Excellent content validity required an I-CVI of 1.0 for at least three experts' analysis [39]. The two-way mixedeffects model with the absolute agreement was used to calculate the intraclass correlation coefficient (ICC) of test-retest reliability. ICC values less than 0.5 were 
interpreted as poor, between 0.5 and 0.75 as moderate, between 0.75 and 0.9 as good, and greater than 0.90 as excellent [40]. Sensitivity, specificity, likelihood ratio for a positive and negative result, positive predictive value, and negative predictive value were calculated using $2 \times 2$ tables. Correlation between T-FRAIL and TFI score was demonstrated by Spearman's correlation coefficient. Each item of the T-FRAIL was evaluated for frailty correlation by the phi correlation coefficient.

\section{Results}

The mean age of the study group $(n=300)$ was 70.4 years (SD 7.3 years), and 144 subjects were male (48.0\%). Frailty was diagnosed with the TFI in 120 patients (40.0\%). Baseline characteristics of the participants are shown in Table 1 . The content validity index of items (I-CVI) was 1.0 for all individual items in the T-FRAIL, indicating excellent content validity [39]. Test-retest reliability assessed in 30 patients yielded an intraclass correlation coefficient of 0.880 (95\% confidence interval 0.76-0.94) which demonstrates good test-retest reliability [40].

T-FRAIL yielded an excellent accuracy against TFI, with an area under the receiving operating characteristic curve of 0.882. A strong correlation between T-FRAIL and TFI was represented by Spearman's correlation coefficient of $0.708(p=<0.001)$. The cutoff-point for TFRAIL of two points showed the highest Youden index of $63.1 \%$ compared to $43.3 \%$ of the original cutoff score of three. (Table 2) The cutoff of two points had a sensitivity of $77.5 \%$ (95\% CI $69.0-84.6)$ and a specificity of 86.1\% (95\%CI 79.6-90.3), which was a better sensitivity than at three points. The positive predictive value of the two-point cutoff was $78.2 \%$ (95\%CI 71.2-83.8), while the negative predictive value was $85.1 \%$ (95\% CI 80.3-88.9).

Elderly individuals with high comorbidities might be excluded from elective surgery due to the risks of the procedure. To explore its diagnostic properties, we modified the T-FRAIL by reducing the threshold of the "illnesses" criterion. A modification that reduced comorbid diseases from five to four (T-FRAIL_M1) and applied a cutoff point score of two improved test parameters (Table 3). Sensitivity was $83.3 \%$ (95\% CI 75.4-89.5) and specificity was 82.8 (95\% CI 76.5-88.0), which is much better than the original T-FRAIL at a cutoff point of three.

"Resistance" and "ambulation" were the best T-FRAIL items to identify frailty. The "resistance" yielded a sensitivity of $72.5 \%$ and specificity of $87.8 \%$, while the "ambulation" yielded a sensitivity of $68.3 \%$ and specificity of 88.9\% (Table 4). Another proposed modification of the T-FRAIL, each questionnaire item was combined into sets of three components (T-FRAIL_M2). A positive response from at least one item out of the three was considered as frail. The "fatigue", "resistance", and "illnesses"
Table 1 Characteristics of study population

\begin{tabular}{|c|c|}
\hline Patient characteristics $(n=300)$ & n (\%) \\
\hline Age (years), mean $\pm S D$ & $70.4 \pm 7.3$ \\
\hline$<70$ years & $152(50.7 \%)$ \\
\hline 70-79years & $105(35.0 \%)$ \\
\hline$\geq 80$ years & $43(14.3 \%)$ \\
\hline \multicolumn{2}{|l|}{ Sex } \\
\hline Male & $144(48.0 \%)$ \\
\hline Female & $156(52.0 \%)$ \\
\hline \multicolumn{2}{|l|}{ Education } \\
\hline Elementary school or lower & $193(64.8 \%)$ \\
\hline High school or above & $105(35.2 \%)$ \\
\hline \multicolumn{2}{|l|}{ Body mass index $\left(\mathrm{kg} / \mathrm{m}^{2}\right)$} \\
\hline Underweight $(<18.5)$ & $20(6.8 \%)$ \\
\hline Normal (18.5-24.9) & $149(50.3 \%)$ \\
\hline Overweight (25-29.9) & $98(33.1 \%)$ \\
\hline Obese $(\geq 30.0)$ & $29(9.8 \%)$ \\
\hline \multicolumn{2}{|l|}{ Cognitive status } \\
\hline No cognitive impairment & $121(40.5 \%)$ \\
\hline Cognitive impairment $(\mathrm{MoCA}<22 / 30)$ & $178(59.5 \%)$ \\
\hline Barthel ADL Index, median (q25,q75) & $95(90,100)$ \\
\hline 0-20 (suggests total dependence) & $2(0.7 \%)$ \\
\hline 21-60 (severe dependence) & $15(5.0 \%)$ \\
\hline 61-90 (moderate dependence) & $90(30.0 \%)$ \\
\hline 91-100 (slight dependence) & $193(64.3 \%)$ \\
\hline \multicolumn{2}{|l|}{ ASA physical status } \\
\hline Class 1 & 19 (6.4\%) \\
\hline Class 2 & $168(56.2 \%)$ \\
\hline Class 3 & $105(35.1 \%)$ \\
\hline Class 4 & $7(2.3 \%)$ \\
\hline \multicolumn{2}{|l|}{ Underlying disease } \\
\hline Diabetes mellitus & $89(29.7 \%)$ \\
\hline Hypertension & $191(63.7 \%)$ \\
\hline Cerebrovascular & $26(8.7 \%)$ \\
\hline Chronic kidney disease & $66(22.0 \%)$ \\
\hline Coronary artery disease & $44(14.7 \%)$ \\
\hline Cirrhosis & $6(2.0 \%)$ \\
\hline Cancer & $70(23.3 \%)$ \\
\hline Peripheral vascular disease & $6(2.0 \%)$ \\
\hline COPD & $8(2.7 \%)$ \\
\hline \multicolumn{2}{|l|}{ Surgical service } \\
\hline General surgery & $2(0.7 \%)$ \\
\hline Hepatobiliary surgery & $3(1.0 \%)$ \\
\hline Minimal invasive surgery & $11(3.7 \%)$ \\
\hline Colorectal surgery & $7(2.3 \%)$ \\
\hline Vascular surgery & $26(8.7 \%)$ \\
\hline Urology surgery & $40(13.4 \%)$ \\
\hline Orthopaedics surgery & $43(14.4 \%)$ \\
\hline Endoscopic surgery & $102(34.2 \%)$ \\
\hline Other & $64(21.5 \%)$ \\
\hline
\end{tabular}


Table 1 (continued)

\begin{tabular}{ll}
\hline Patient characteristics $(\boldsymbol{n}=\mathbf{3 0 0})$ & $\mathbf{n}(\%)$ \\
\hline Smoking & \\
$\quad$ Non \& Ex-smoker & $285(95.0 \%)$ \\
$\quad$ Current-smoker & $15(5.0 \%)$ \\
Alcohol & \\
$\quad$ No & $275(91.7 \%)$ \\
Drink & $25(8.3 \%)$ \\
Thai Frailty Index & \\
Robust & $180(60.0 \%)$ \\
Frail & $120(40.0 \%)$ \\
T-FRAlL & \\
Fatigue & $44(14.7 \%)$ \\
Resistance & $109(36.3 \%)$ \\
Ambulation & $102(34.0 \%)$ \\
Illness & $21(7.0 \%)$ \\
Loss of weight & $93(31.0 \%)$ \\
\hline
\end{tabular}

Abbreviations: MoCA The Montreal Cognitive Assessment; ADL Activities of Daily Living, ASA the American Society of Anesthesiologists, COPD Chronic obstructive pulmonary disease, T-FRAIL The Thai version of the Simple Frailty Questionnaire combination showed the highest Youden's index of $66.4 \%$ with a sensitivity of $85.8 \%$ and a specificity of $80.6 \%$. All modified questionnaires with three items were analyzed for sensitivity and specificity in comparison with the TFI. (Table 5).

\section{Discussion}

The T-FRAIL was translated with a standardized protocol and achieved satisfying psychometric properties, including good or excellent content validity and test-retest reliability. The questionnaire was tested against the TFI and achieved excellent accuracy. Previous validity studies of the simple frailty questionnaire in other contexts have yielded varying results due to different methodologies and different populations.

The original FRAIL scale, using positive at three out of five item criteria, showed a significant correlation with impaired function in a cross sectional cohort [5], but the study did not investigate the correlation with the reference standard or using a different cutoff point. Nevertheless, several studies using various cutoff points

Table 2 Frailty cut-point for original T-FRAIL with TFI as the reference standard

\begin{tabular}{lllllll}
\hline Frailty cut-points & $\begin{array}{l}\text { Number of frail } \\
\text { patients (\%) }\end{array}$ & Sensitivity (\%) & Specificity (\%) & $\begin{array}{l}\text { Youden's Index } \\
\text { (\%) }\end{array}$ & PPV (\%) & NPV (\%) \\
\hline$\geq 1$ & $182(60.7 \%)$ & 93.3 & 61.1 & 54.4 & 61.5 & 93.2 \\
$\geq 2$ & $119(39.7 \%)$ & 77.5 & 85.6 & 63.1 & 78.2 & 85.1 \\
$\geq 3$ & $57(19.0 \%)$ & 45.0 & 98.3 & 43.3 & 94.7 & 72.8 \\
$\geq 4$ & $10(3.3 \%)$ & 8.3 & 100 & 8.3 & 100 & 62.1 \\
\hline
\end{tabular}

Abbreviations: T- FRAIL The Thai version of the Simple Frailty Questionnaire, TFI The Thai Frailty Index, PPV positive predictive value, NPV negative predictive value

Table 3 Frailty cut-point forT-FRAIL_M1 with TFI as the reference standard

\begin{tabular}{lllllll}
\hline Frailty cut-points & $\begin{array}{l}\text { Number of frail } \\
\text { patients (\%) }\end{array}$ & Sensitivity (\%) & Specificity (\%) & $\begin{array}{l}\text { Youden's Index } \\
\text { (\%) }\end{array}$ & PPV (\%) & NPV (\%) \\
\hline$\geq 1$ & $189(63.0 \%)$ & 94.2 & 57.8 & 52 & 59.8 & 93.7 \\
$\geq 2$ & $131(43.7 \%)$ & 83.3 & 82.8 & 66.1 & 76.3 & 88.2 \\
$\geq 3$ & $69(23.0 \%)$ & 53.3 & 97.2 & 50.5 & 92.8 & 75.8 \\
$\geq 4$ & $26(8.7 \%)$ & 20.8 & 99.4 & 20.2 & 96.2 & 65.3 \\
\hline
\end{tabular}

Abbreviations: T-FRAIL_M1 modified T-FRAIL by reducing "illness" criterion to 4 or more diseases

Table 4 Sensitivity, specificity, and Youden's index of each original T-FRAIL item

\begin{tabular}{|c|c|c|c|c|c|}
\hline & \multicolumn{2}{|l|}{ TFI } & \multicolumn{3}{|l|}{ SFQ Items } \\
\hline & Robust $(n=180)$ & FRAIL $(n=120)$ & Sensitivity & Specificity & Youden's index \\
\hline Fatigue & $11(6.1 \%)$ & $33(27.5 \%)$ & $27.5 \%$ & $93.9 \%$ & 21.4 \\
\hline Resistance & $22(12.2 \%)$ & 87 (72.5\%) & $72.5 \%$ & $87.8 \%$ & 60.3 \\
\hline Ambulation & $20(11.1 \%)$ & $82(68.3 \%)$ & $68.3 \%$ & $88.9 \%$ & $57.2 \%$ \\
\hline Illnesses & $4(2.2 \%)$ & $18(15.0 \%)$ & $15.0 \%$ & $97.8 \%$ & $12.8 \%$ \\
\hline Loss of weight & 43 (23.9\%) & 50 (41.7\%) & $41.7 \%$ & $76.1 \%$ & 17.8 \\
\hline
\end{tabular}

Abbreviations: T-FRAIL The Thai version of the Simple Frailty Questionnaire, TFI The Thai Frailty Index, SFQ Items The Simple Frailty Questionnaire items 
Table 5 Sensitivity, specificity and Youden's index in T-FRAIL_M2

\begin{tabular}{|c|c|c|c|}
\hline & \multicolumn{3}{|c|}{ Combination of SFQ Items } \\
\hline & Sensitivity (\%) & Specificity (\%) & $\begin{array}{l}\text { Youden's } \\
\text { index } \\
(\%)\end{array}$ \\
\hline $\begin{array}{l}\text { 1,2,3; positive at least } \\
1 \text { item }\end{array}$ & $83.3 \%$ & $78.3 \%$ & 61.6 \\
\hline $\begin{array}{l}\text { 1,2, 4; positive at least } \\
1 \text { item }\end{array}$ & $85.8 \%$ & $80.6 \%$ & 66.4 \\
\hline $\begin{array}{l}\text { 1,2,5; positive at least } \\
1 \text { item }\end{array}$ & $90.8 \%$ & $64.4 \%$ & 55.2 \\
\hline $\begin{array}{l}\text { 1,3,4; positive at least } \\
1 \text { item }\end{array}$ & $79.2 \%$ & $80.6 \%$ & 59.8 \\
\hline $\begin{array}{l}\text { 1,3,5; positive at least } \\
1 \text { item }\end{array}$ & $85.8 \%$ & $65.6 \%$ & 51.4 \\
\hline $\begin{array}{l}1,4,5 ; \text { positive at least } \\
1 \text { item }\end{array}$ & $66.7 \%$ & $71.7 \%$ & 38.4 \\
\hline $\begin{array}{l}2,3,4 \text {; positive at least } \\
1 \text { item }\end{array}$ & $84.2 \%$ & $81.1 \%$ & 65.3 \\
\hline $\begin{array}{l}2,3,5 ; \text { positive at least } \\
1 \text { item }\end{array}$ & $88.3 \%$ & $64.4 \%$ & 52.7 \\
\hline $\begin{array}{l}2,4,5 ; \text { positive at least } \\
1 \text { item }\end{array}$ & $89.2 \%$ & $65.6 \%$ & 54.8 \\
\hline $\begin{array}{l}3,4,5 \text {; positive at least } \\
1 \text { item }\end{array}$ & $85.0 \%$ & $67.8 \%$ & 52.8 \\
\hline
\end{tabular}

Note: 1 represents "Fatigue"; 2 represents "Resistance"; 3 represents "Ambulation"; 4 represents "Illnesses"; 5 represents "Loss of Weight" Abbreviations: T-FRAIL_M2 modified T-FRAIL by the combination of three components with positive results if presence any feature from three parameters, SFQ Items The Simple Frailty Questionnaire items

were identified among later cross-culturally adapted versions of the FRAIL scale [27, 28, 41]. For example, using three points to diagnose frailty, the Korean (K-FRAIL) was tested against a comprehensive geriatric assessment-based frailty index as a reference standard and demonstrated excellent (90\%) sensitivity but low (33\%) specificity [27]. Meanwhile, the FRAIL-AR, using similar 3-point cutoff score, was compared with Fried Frailty Index with sensitivity and specificity of 72 and $67 \%$, respectively [41]. Using a three-point cutoff score, we observed a significantly lower sensitivity with very high specificity, which may not be optimal for a screening tool.

Nevertheless, some studies in Chinese and Japanese populations (FRAIL-J) using a 2-point cutoff have yielded comparable results. In the Chinese study, A 2-point cutoff Chinese FRAIL scale represented a sensitivity of $90 \%$ and a specificity of $86 \%$ compared to the Fried Frailty Phenotype [28]. Similarly, the FRAIL-J was compared to Fried Frailty phenotype with a sensitivity of $77.8 \%$ and specificity of $88.9 \%$ [42]. Our modification using the original T-FRAIL at a cutoff score of two showed similar properties to the Japanese version. However, further modification by reducing the number of medical illnesses (T-FRAIL_M1), improves sensitivity from 77 to $83 \%$ with a better Youden's index at $66 \%$. Moreover, further modification of the cutoff point to be as low as one point for both the original T-FRAIL and T-FRAIL_M1 would yield a higher sensitivity of 93 and $94 \%$, respectively, with a specificity of around $60 \%$. This provides better properties compared to the 3-point score of K-FRAIL [27].

Another proposed method to modify the T-FRAIL modification is to lower the criterion of the questionnaire. According to the Study of Osteoporotic Fractures index (the SOF index) for frailty diagnosis, weight loss, inability to rise from a chair, and poor energy are sufficient to classify pre-frail and frail patients in comparison with the Fried Frailty phenotype. The SOF index also proved the relationship to clinical outcomes including falls, disability, fracture, and mortality in two large studies $[43,44]$. We also modified the T-FRAIL instrument to improve its psychometric properties using a combination of three components (T-FRAIL_M2), resulting in a sensitivity and specificity of around $80 \%$.

Although the T-FRAIL_M1 and the T-FRAIL_M2 improved sensitivity of the test, overall test properties were similar to the T-FRAIL. The AuROC of T-FRAIL M1 and T-FRAIL_M2 were around 83\%, while the original one was $81 \%$. Despite its little difference, the modification leads to more sensitivity which serves author's propose to use the questionnaire for screening test rather than confirmation test. Moreover, the T-FRAIL_M2, due to its simplicity, would be useful for primary care setting in rural area, where many citizens had lower education level. According to the Table 5, despite omitting the "loss of weight" criteria, the T-FRAIL_M2 ("fatigue", "resistance" and "illnesses") still had high performance for frailty diagnosing. This fact emphasized the T-FRAIL_M2 advantages in Thai context, whose most elders could not recall their previous bodyweight.

An optimal pre-operative screening tool should have high sensitivity and an acceptable specificity. The cutoff score of one point from five items from the original version of T-FRAIL and T-FRAIL_M1 would serve this purpose. Nevertheless, in resource limited settings, an alternative option could be the T-FRAIL_M1 with a 2-point cutoff score or T-FRAIL_M2 that provides reasonable sensitivity and better specificity.

The strengths of our study were the use of reference standard in addition to the standard translational procedure. The reference standard in this study was derived from large scale population in our country and has been studied for the validity in the local setting. Nevertheless, additional studies of predictive validity in stratifying risk in the elderly would be valuable. Further study to identify the elderly who might experience adverse outcomes or benefit from specific interventions using this test are needed. Limitation of the study was in relation 
to the studying in one setting in single center. All of our subjects were selected from elective surgery, the generalizability of the findings to other settings might be an issue. Additional studies among older people in similar setting at other center and in other medical context would ascertain the usability of the test.

\section{Conclusion}

The T-FRAIL demonstrated good validity and reliability for diagnosing frailty in older people preparing for elective surgery. A modified T-FRAIL using a lower cutoff point yielded higher sensitivity than the original cutoff point but gave lower specificity. Another modification was a reduction of the illnesses criterion or a combination with sets of three components increased sensitivity, while preserved excellent specificity of the test, making it suitable for use as a screening tool in practical use. A prospective study is needed to determine if the T-FRAIL and its modified versions may be useful to predict mortality, disability, or other clinical outcomes in different settings.

\section{Abbreviations}

T- FRAIL: Thai version of the Simple Frailty Questionnaire; T-FRAIL_M1: Modified T-FRAIL by reducing "illnesses" criteria to 4 or more diseases; T-FRAIL_M2: Modified T-FRAIL by combination with sets of three components; TFI: Thai Frailty Index; I-CVI: Content validity index for items; FRAIL: Simple Frailty Questionnaire; ICC: Intraclass correlation coefficient; K-FRAIL: Korean version of the FRAIL scale; FRAIL-AR: Arabic version of the FRAIL scale; FRAIL-J: Japanese version of the FRAIL scale; SOF: Study of Osteoporotic Fractures.

\section{Acknowledgments}

This study was facilitated by the Integrated Perioperative Geriatric Excellent Research Center, Faculty of Medicine, Siriraj Hospital, Mahidol University, Bangkok, Thailand. This research project is supported by Siriraj research fund, Faculty of Medicine Siriraj Hospital, Mahidol University. The authors thank Miss Rinrada Preedachitkul of the Siriraj Hospital Health Policy Unit, Mahidol University, for her assistance with statistical analyses.

\section{Authors' contributions}

WT, TW were involved in the conceptual design of this study analysis and interpretation of data, drafting of the manuscript, critical revision and feedback. WM data collection and drafting of the manuscript. VS supervisor and director of the study, manuscript review and critical revision. AS, WA, PL and PS manuscript review and critical revision. RR data collection, data curation, and manuscript formatting. All authors were approved the submission and agreed to be personally accountable for their own contributions.

\section{Funding}

This research project was supported by Faculty of Medicine Siriraj Hospital, Mahidol University (Grant Number: R01639001). The funding body has no role in the study design, data analysis and data reporting.

\section{Availability of data and materials}

The datasets used and/or analyzed during the current study are available from the corresponding author on reasonable request.

\section{Declarations}

\section{Ethics approval and consent to participate}

This study was conducted in accordance with the Declaration of Helsinki and was approved by the Institutional Review Board, Faculty of Medicine Siriraj
Hospital, Bangkok, Thailand (Certification of approval reference number: Si 397/2018). Inform consent had been signed by participants or their legalized representatives prior to any data collection.

\section{Consent for publication}

Not applicable.

\section{Competing interests}

The authors declare that they have no competing interests.

\section{Author details}

'Department of Medicine, Faculty of Medicine Khon Kaen University, Khon Kaen 40002, Thailand. ${ }^{2}$ Department of Anesthesiology, Faculty of Medicine Khon Kaen University, Khon Kaen 40002, Thailand. ${ }^{3}$ Division of Geriatric Medicine, Department of Medicine, Faculty of Medicine Siriraj Hospital, Mahidol University, Bangkok 10700, Thailand. ${ }^{4}$ Integrated Perioperative Geriatric Excellent Research Center, Faculty of Medicine, Siriraj Hospital, Mahidol University, Bangkok 10700, Thailand. ${ }^{5}$ Department of Anesthesiology, Faculty of Medicine Siriraj Hospital, Mahidol University, Bangkok 10700, Thailand. ${ }^{6}$ Department of Community Medicine, Faculty of Medicine Ramathibodi Hospital, Mahidol University, Bangkok 10400, Thailand. 'Division of Geriatric Medicine, Department of Medicine, Faculty of Medicine Khon Kaen University, Khon Kaen 40002, Thailand

Received: 11 October 2021 Accepted: 21 February 2022

Published online: 28 February 2022

\section{References}

1. Fried LP, Tangen CM, Walston J, Newman AB, Hirsch C, Gottdiener J, et al. Frailty in older adults: evidence for a phenotype. J Gerontol A Biol Sci Med Sci. 2001;56(3):M146-56. https://doi.org/10.1093/gerona/56.3.m146.

2. Clegg A, Young J, lliffe S, Rikkert MO, Rockwood K. Frailty in elderly people. Lancet. 2013;381(9868):752-62. https://doi.org/10.1016/S01406736(12)62167-9.

3. Fan J, Yu C, Guo Y, Bian Z, Sun Z, Yang L, et al. Frailty index and all-cause and cause-specific mortality in Chinese adults: a prospective cohort study. Lancet Public Health. 2020;5(12):e650-60. https://doi.org/10.1016/ S2468-2667(20)30113-4

4. Hanlon P, Nicholl BI, Jani BD, Lee D, McQueenie R, Mair FS. Frailty and pre-frailty in middle-aged and older adults and its association with multimorbidity and mortality: a prospective analysis of 493737 UK biobank participants. Lancet Public Health. 2018;3(7):e323-32. https://doi.org/10. 1016/S2468-2667(18)30091-4

5. Morley JE, Malmstrom TK, Miller DK. A simple frailty questionnaire (FRAIL) predicts outcomes in middle aged African Americans. J Nutr Health Aging. 2012;16(7):601-8. https://doi.org/10.1007/s12603-012-0084-2.

6. Sieber CC. Frailty - from concept to clinical practice. Exp Gerontol. 2017;87(Pt B):160-7. https://doi.org/10.1016/j.exger.2016.05.004.

7. Fried LP, Ferrucci L, Darer J, Williamson JD, Anderson G. Untangling the concepts of disability, frailty, and comorbidity: implications for improved targeting and care. J Gerontol A Biol Sci Med Sci. 2004;59(3):255-63. https://doi.org/10.1093/gerona/59.3.m255.

8. Sanchez-Garcia S, Garcia-Pena C, Salva A, Sanchez-Arenas R, GranadosGarcia V, Cuadros-Moreno J, et al. Frailty in community-dwelling older adults: association with adverse outcomes. Clin Interv Aging. 2017;12:1003-11. https://doi.org/10.2147/CIA.S139860.

9. de Vries OJ, Peeters GM, Lips P, Deeg DJ. Does frailty predict increased risk of falls and fractures? A prospective population-based study. Osteoporos Int. 2013;24(9):2397-403. https://doi.org/10.1007/s00198-013-2303-z.

10. Kojima G. Frailty as a predictor of hospitalisation among communitydwelling older people: a systematic review and meta-analysis. J Epidemiol Community Health. 2016;70(7):722-9. https://doi.org/10.1136/ jech-2015-206978.

11. Bartley MM, Geda YE, Christianson TJ, Pankratz VS, Roberts RO, Petersen RC. Frailty and mortality outcomes in cognitively Normal older people: sex differences in a population-based study. J Am Geriatr Soc 2016;64(1):132-7. https://doi.org/10.1111/jgs.13821.

12. Amrock LG, Neuman MD, Lin HM, Deiner $S$. Can routine preoperative data predict adverse outcomes in the elderly? Development and validation of 
a simple risk model incorporating a chart-derived frailty score. J Am Coll Surg. 2014;219(4):684-94. https://doi.org/10.1016/j.jamcollsurg.2014.04. 018.

13. Lin HS, McBride RL, Hubbard RE. Frailty and anesthesia - risks during and post-surgery. Local Reg Anesth. 2018;11:61-73. https://doi.org/10.2147/ LRA.S142996.

14. Tomlinson SB, Piper K, Kimmell KT, Vates GE. Preoperative frailty score for 30-day morbidity and mortality after cranial neurosurgery. World Neurosurg. 2017;107:959-65. https://doi.org/10.1016/j.wneu.2017.07.081.

15. Makary MA, Segev DL, Pronovost PJ, Syin D, Bandeen-Roche K, Patel P, et al. Frailty as a predictor of surgical outcomes in older patients. J Am Coll Surg. 2010;210(6):901-8. https://doi.org/10.1016/j.jamcollsurg.2010. 01.028 .

16. Bagnall NM, Faiz O, Darzi A, Athanasiou T. What is the utility of preoperative frailty assessment for risk stratification in cardiac surgery? Interact Cardiovasc Thorac Surg. 2013;17(2):398-402. https://doi.org/10.1093/ icvts/ivt197.

17. Sepehri A, Beggs T, Hassan A, Rigatto C, Shaw-Daigle C, Tangri N, et al. The impact of frailty on outcomes after cardiac surgery: a systematic review. J Thorac Cardiovasc Surg. 2014;148(6):3110-7. https://doi.org/10.1016/j. jtcvs.2014.07.087.

18. Ethun CG, Bilen MA, Jani AB, Maithel SK, Ogan K, Master VA. Frailty and cancer: implications for oncology surgery, medical oncology, and radiation oncology. CA Cancer J Clin. 2017;67(5):362-77. https://doi.org/10. 3322/caac.21406.

19. Alvarez-Nebreda ML, Bentov N, Urman RD, Setia S, Huang JC, Pfeifer K, et al. Recommendations for preoperative Management of Frailty from the Society for Perioperative Assessment and Quality Improvement (SPAQI). J Clin Anesth. 2018;47:33-42. https://doi.org/10.1016/j.jclinane.2018.02. 011.

20. Chan SP, Ip KY, Irwin MG. Peri-operative optimisation of elderly and frail patients: a narrative review. Anaesthesia. 2019;74(Suppl 1):80-9. https:// doi.org/10.1111/anae.14512.

21. Amrock LG, Deiner S. Perioperative frailty. Int Anesthesiol Clin. 2014;52(4):26-41. https://doi.org/10.1097/AIA.0000000000000026.

22. Dhesi JK, Lees NP, Partridge JS. Frailty in the perioperative setting. Clin Med (Lond). 2019;19(6):485-9. https://doi.org/10.7861/clinmed. 2019-0283.

23. Chow WB, Rosenthal RA, Merkow RP, Ko CY, Esnaola NF. American college of surgeons national surgical quality improvement $\mathrm{P}$, american geriatrics S: optimal preoperative assessment of the geriatric surgical patient: a best practices guideline from the american college of surgeons national surgical quality improvement program and the american geriatrics society. J Am Coll Surg. 2012;215(4):453-66. https://doi.org/10.1016/j.jamco Illsurg.2012.06.017.

24. Dent E, Lien C, Lim WS, Wong WC, Wong CH, Ng TP, et al. The asia-pacific clinical practice guidelines for the management of frailty. J Am Med Dir Assoc. 2017;18(7):564-75. https://doi.org/10.1016/j.jamda.2017.04.018.

25. Morley JE, Vellas B, van Kan GA, Anker SD, Bauer JM, Bernabei R, et al. Frailty consensus: a call to action. J Am Med Dir Assoc. 2013;14(6):392-7. https://doi.org/10.1016/j.jamda.2013.03.022.

26. Hoogendijk EO, Afilalo J, Ensrud KE, Kowal P, Onder G, Fried LP. Frailty: implications for clinical practice and public health. Lancet. 2019;394(10206):1365-75. https://doi.org/10.1016/S0140-6736(19) 31786-6.

27. Jung HW, Yoo HJ, Park SY, Kim SW, Choi JY, Yoon SJ, et al. The Korean version of the FRAIL scale: clinical feasibility and validity of assessing the frailty status of Korean elderly. Korean J Intern Med. 2016;31 (3):594-600. https://doi.org/10.3904/kjim.2014.331

28. Dong L, Qiao X, Tian X, Liu N, Jin Y, Si H, et al. Cross-cultural adaptation and validation of the FRAIL scale in Chinese community-dwelling older adults. J Am Med Dir Assoc. 2018;19(1):12-7. https://doi.org/10.1016/j. jamda.2017.06.011.

29. Rosas-Carrasco O, Cruz-Arenas E, Parra-Rodriguez L, Garcia-Gonzalez Al, Contreras-Gonzalez LH, Szlejf C. Cross-cultural adaptation and validation of the FRAIL scale to assess frailty in Mexican adults. J Am Med Dir Assoc. 2016;17(12):1094-8. https://doi.org/10.1016/j.jamda.2016.07.008.

30. Srinonprasert V, Chalermsri C, Aekplakorn W. Frailty index to predict all-cause mortality in Thai community-dwelling older population: a result from a National Health Examination Survey cohort. Arch Gerontol Geriatr. 2018;77:124-8. https://doi.org/10.1016/j.archger.2018.05.002.
31. Searle SD, Mitnitski A, Gahbauer EA, Gill TM, Rockwood K. A standard procedure for creating a frailty index. BMC Geriatr. 2008;8:24. https://doi. org/10.1186/1471-2318-8-24.

32. Beaton DE, Bombardier C, Guillemin F, Ferraz MB. Guidelines for the process of cross-cultural adaptation of self-report measures. Spine (Phila Pa 1976). 2000;25(24):3186-91. https://doi.org/10.1097/00007632-20001 2150-00014.

33. Sun V, Burhenn PS, Lai L, Hurria A. The impact of comorbidity on surgical outcomes in older adults with Cancer. Semin Oncol Nurs. 2017;33(1):806. https://doi.org/10.1016/j.soncn.2016.11.008.

34. Paya-Llorente C, Martinez-Lopez E, Sebastian-Tomas JC, Santarrufina-Martinez S, de' Angelis N, Martinez-Perez A. The impact of age and comorbidity on the postoperative outcomes after emergency surgical management of complicated intra-abdominal infections. Sci Rep. 2020;10(1):1631. https://doi.org/10.1038/s41598-020-58453-1.

35. Campbell PG, Yadla S, Nasser R, Malone J, Maltenfort MG, Ratliff JK. Patient comorbidity score predicting the incidence of perioperative complications: assessing the impact of comorbidities on complications in spine surgery. J Neurosurg Spine. 2012;16(1):37-43. https://doi.org/10.3171/ 2011.9.SPINE11283.

36. Woelfel IA, Fernandez LJ, Idowu MO, Takabe K. A high burden of comorbid conditions leads to decreased survival in breast cancer. Gland Surg. 2018;7(2):216-27. https://doi.org/10.21037/gs.2018.02.03.

37. Stairmand J, Signal L, Sarfati D, Jackson C, Batten L, Holdaway M, et al. Consideration of comorbidity in treatment decision making in multidisciplinary cancer team meetings: a systematic review. Ann Oncol. 2015;26(7):1325-32. https://doi.org/10.1093/annonc/mdv025.

38. Jespersen CG, Norgaard M, Jacobsen JB, Borre M. Patient comorbidity is associated with conservative treatment of localized prostate cancer. Scand J Urol. 2015;49(5):366-70. https://doi.org/10.3109/21681805.2015. 1026936.

39. Polit DF, Beck CT. The content validity index: are you sure you know what's being reported? Critique and recommendations. Res Nurs Health. 2006;29(5):489-97. https://doi.org/10.1002/nur.20147.

40. Koo TK, Li MY. A guideline of selecting and reporting intraclass correlation coefficients for reliability research. J Chiropr Med. 2016;15(2):155-63. https://doi.org/10.1016/j.jcm.2016.02.012.

41. Alqahtani BA, Nasser TA. Assessment of frailty in Saudi communitydwelling older adults: validation of measurements. Ann Saudi Med. 2019;39(3):197-204. https://doi.org/10.5144/0256-4947.2019.197.

42. Kim S, Kim M, Jung HW, Won CW. Development of a frailty phenotype questionnaire for use in screening community-dwelling older adults. J Am Med Dir Assoc. 2020;21(5):660-4. https://doi.org/10.1016/j.jamda. 2019.08.028

43. Ensrud KE, Ewing SK, Cawthon PM, Fink HA, Taylor BC, Cauley JA, et al. A comparison of frailty indexes for the prediction of falls, disability, fractures, and mortality in older men. J Am Geriatr Soc. 2009;57(3):492-8. https://doi.org/10.1111/j.1532-5415.2009.02137.x.

44. Ensrud KE, Ewing SK, Taylor BC, Fink HA, Cawthon PM, Stone KL, et al. Comparison of 2 frailty indexes for prediction of falls, disability, fractures, and death in older women. Arch Intern Med. 2008;168(4):382-9. https:// doi.org/10.1001/archinternmed.2007.113.

\section{Publisher's Note}

Springer Nature remains neutral with regard to jurisdictional claims in published maps and institutional affiliations. 